\title{
Finite Element Analysis of the Multilayered Honeycomb Composite Material Subjected to Impact Loading
}

\author{
RAUL CORMOS ${ }^{1}$, HORIA PETRESCU ${ }^{1}$, ANTON HADAR ${ }^{1,2 *}$, GEORGE MIHAIL ADIR $^{13}$, HORIA GHEORGHIU ${ }^{1}$ \\ 1Politehnica University of Bucharest, Department of Strenght of Materials, 313 Splaiul Independen kei, 060032, Bucharest, Romania \\ ${ }^{2}$ Academy of Romanian Scientists, 54 Splaiul Independentei, 050085, Bucharest, Romania \\ ${ }^{3}$ University Politehnica of Bucharest, Faculty of Engineering and Management of Technological Systems, Theory of Mechanisms \\ and Robots Department, 313 Splaiul Independenpei, 060042, Bucharest, Romania
}

\begin{abstract}
The main purpose of this paper is the study the behavior of four multilayered composite material configurations subjected to different levels of low velocity impacts, in the linear elastc domain of the materials, using experimental testing and finite element simulation. The experimental results obtained after testing, are used to validate the finite element models of the four composite multilayered honeycomb structures, which makes possible the study, using only the finite element method, of these composite materials for a give application.
\end{abstract}

Keywords: multilayered honeycomb composite materials, low velocity impac testingt, experimental study, finite element simulation

The continuous development of materials used in engineering applications, has allowed the improvement of traditional mechanical engineering areas and the development of new ones.

The appearance and usage of composite materials in mechanical engineering has resulted in many improvements of industry leading domains [1]. In [2], the non-homogenous nature of a honeycomb sandwich panel that significantly affects the structural performance during hypervelocity impact with space debris is presented. C.L. Wu and C.T. Sun evaluate the low velocity impact in composite sandwich beams, concluding that major modes of damage included matrix cracking and delamination in the face laminate and yielding in the core [3]. Sandwich composite structures with honeycomb core are extensively used in many performance demanding areas of mechanical engineering, such as: aerospace, naval and astronautics industry. The major factor which makes the sandwich structures extensively used is their high strength and low weight.

The ongoing development of sandwich structures has resulted in many new materials with different mechanical properties. Such developments have been achieved by the usage of nonconventional honeycomb cores [4].

Studying the behavior of honeycomb structures subjected to impact loading represents a strategic domain. As applications in this area, the outer hall of spacecraft structures can be mentioned, which is subjected to impact loading by meteorites which are traveling in space with high speed. In [5], high energy impact tests were carried out on E-glass phenolic impregnated sandwich structures in order to obtain a finite element procedure thus calibrating the basic properties for the adopted material model to take into account the main damage mechanisms occurring during the impact tests. Ping Liu Yan Liu Xiong Zhang propose in [6] an improved shielding structure with double honeycomb cores for hyper-velocity impact.

The impact load has been classified by many criteria, the most used is by the impact speed [7-10]. Impact loading on composite structures represents a strategic research domain especially for low velocity impact.

Low velocity impact (LVI) is considered when the impact speed is not higher than $20 \mathrm{~m} / \mathrm{s}$, [ 7]. During LVI, the main loading, for composite sandwich structure is bending. G. Reyes [11] revealed that low velocity impact behaviour of the sandwich systems investigated using an instrumented impact exhibit excellent energy absorbing characteristics under dynamic loading conditions. Thus for a for a composite sandwich structure, which undergoes $\mathrm{LVI}$, it has been established the main failure modes width the increase of impact energy. These failure modes are: local indentation, delamination, and buckling of the honeycomb core followed by penetration of the composite structure $[12,13]$.

Throw many experimental analysis it has been determined that the behavior of sandwich structures subjected to impact loading is influenced on the honeycomb core configuration used for the composite material [14-16] but in [17] it was shown that the partition of the incident energy depends strongly on the geometry of the impacting projectile.

In the case of low velocity impact ithas been determined that the core has an important role in the distribution of the impact energy throughout the entire composite structure. At beginning of the LVI domain, the most loaded component of the honeycomb structures is the contact sheet of the sandwich structure, accumulating over $70 \%$ of the impact energy. As the impact speed increases, towards the end of the LVI, the absorbed energy is distributed between the contact area and the lower sheet of the sandwich structure [14].

The main purpose of this article is to validate the finite element models of four multilayered honeycomb composite materials subjected to impact loading. The finite element model is made using the Ansys finite element software. The geometrical model of the multilayered honeycomb composite material is made using Solidworks software.

\section{Multilayered honeycomb composite material description}

The multilayered honeycomb composite materials are made out of five layers. Two external layers are made of double layered woven laminated composites impregnated in polyester resin and two honeycomb layers separated by a single layer of woven laminated composite. The honeycomb cores used for the multilayered composite materials, are of two types, paper honeycomb and impregnated paper honeycomb in polyester resign, thus resulting four multilayer honeycomb composite material

\footnotetext{
*email: anton.hadar@upb.ro; antonhadar@yahoo.com
} 


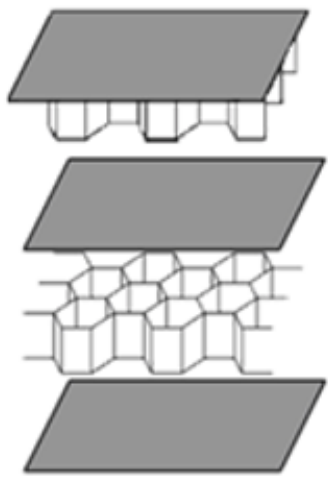

1.a

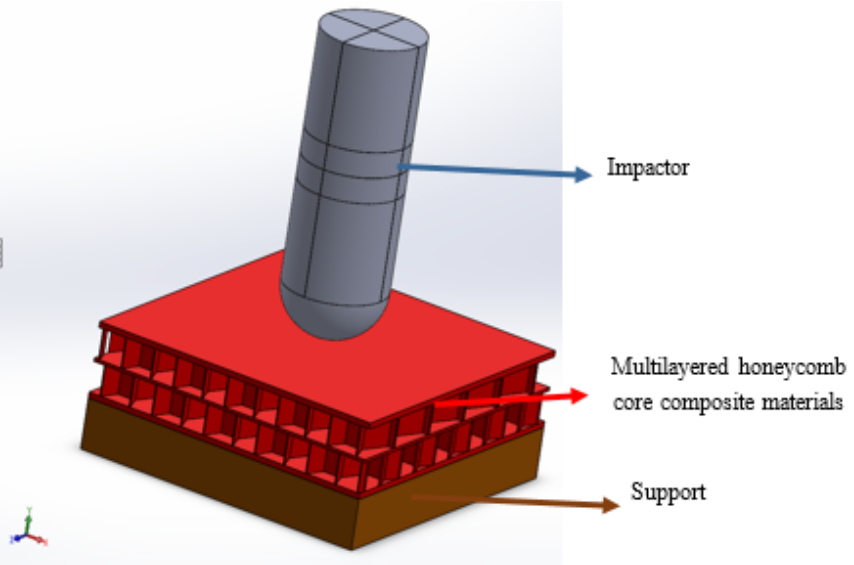

Fig.2. Finite element model

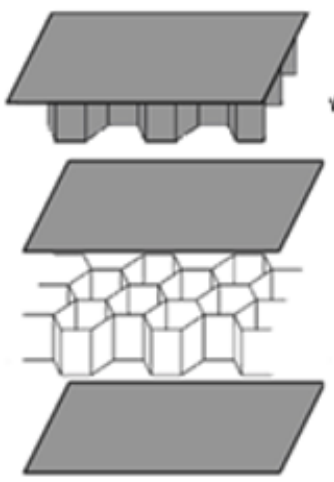

1.c

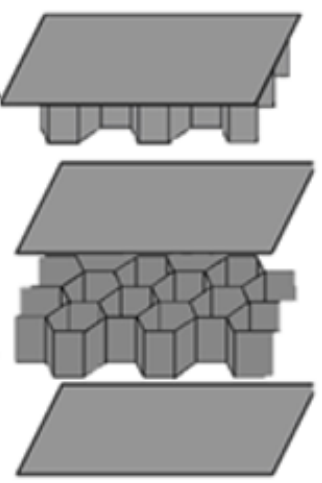

1.d
Fig. 1. Multilayered honeycomb composite materials configurations

$\mathrm{mm}$ in diameter. The impactor has a semispherical head with a diameter of $20 \mathrm{~mm}$, (fig. 2).

The geometry of the honeycomb core is presented in figure 3 .

The wall thicknesses are different for paper core honeycomb and impregnated paper core honeycomb. For paper core honeycomb the wall thickness is $0.23 \mathrm{~mm}$ and for impregnated paper core $0.55 \mathrm{~mm}$.

Because the position of the two honeycomb cores related to each other are unknown, four geometrical models have been made, considering four extreme positions of the two honeycomb cores related to each other.

The first configuration has both honeycomb cores overlapped (fig. 4).

The second geometrical configuration has a $3.53 \mathrm{~mm}$ distance between the two cores on the $\mathrm{X}$ axis direction, (fig. 5).

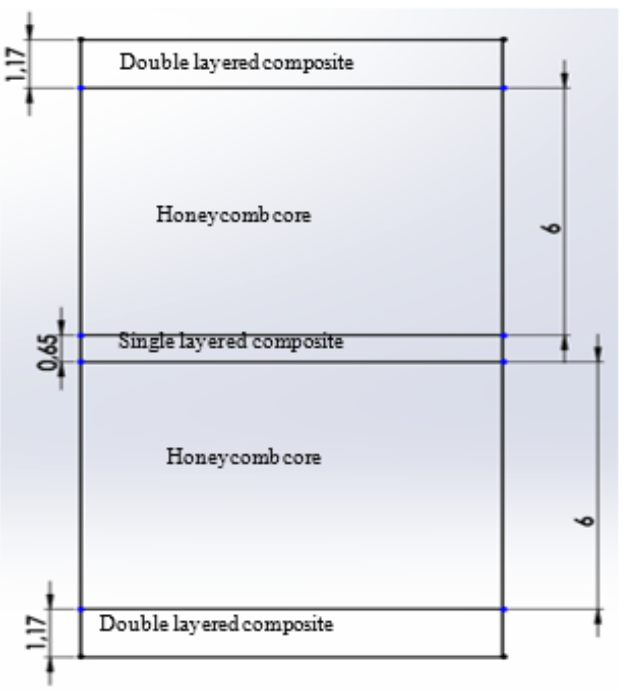

configurations. The four configuration of multilayered composite material, are different from one another, by the two honeycomb cores types, used in their structure. The first type of multilayered honeycomb core composite material has both honeycomb cores made of paper, figure 1.a, the second one has the first honeycomb core made of paper and the second core made of impregnated paper, figure $1 . b$, the third multilayered honeycomb composite material has the first layer made of impregnated paper, and the second layer from paper, figure 1.c and the last multilayered honeycomb composite material has both honeycomb layers made of impregnated paper, (fig. 1d).

\section{Finite element and geometrical models}

The geometry of the model contains three main parts: the support on which the multilayered honeycomb composite material is placed, the multilayered honeycomb composite material and the impactor. The support has the dimensions $60 \times 60 \mathrm{~mm}$ and has a hole in the center of 40
Fig. 3. Honeycomb core geometry 

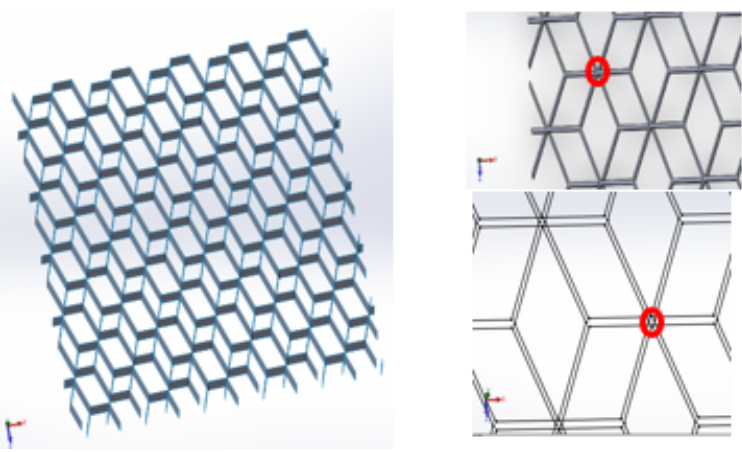

Fig. 5. Second geometrical configuration for the multilayered honeycomb composite material

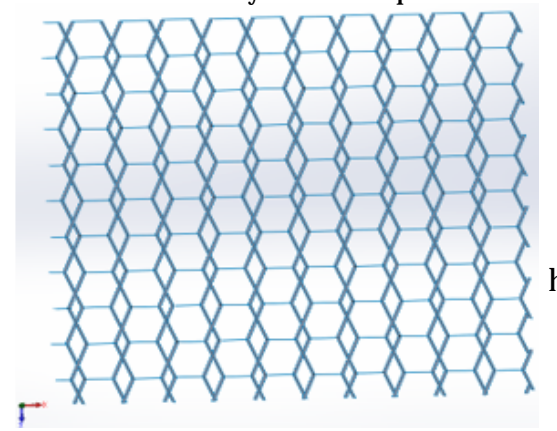

Fig. 6. Third geometrical configuration for the multilayered honeycomb composite material

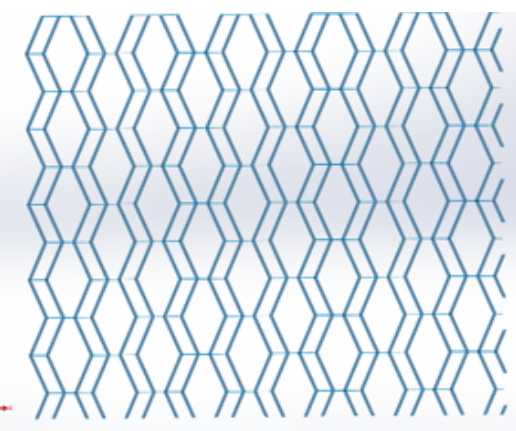

Fig. 7. Fourth geometrical configuration for multilayered honeycomb composite material

The mass of the impactor was taken into account by modifying the steel density to the value of $379700 \mathrm{~kg} / \mathrm{m}^{3}$, which corresponds to a mass of $6.76 \mathrm{~kg}$, for the finite element model. The support is made from the same steel material. The steel used for both the impactor and the support has standard mechanical properties.

\section{Experimental device}

To make the impact tests on the multilayered honeycomb composite materials, a drop tower was designed in the University Politehnica of Bucharest, figure 8. The drop tower is made of impactor region with a mass of $6.76 \mathrm{~kg}$, an accelerometer and the impactor head.
Table 1

MECHANICAL PROPERTIES OF MATERIALS

\begin{tabular}{|c|c|c|}
\hline Material name & $\begin{array}{c}\text { Young Modulus } \\
(\mathrm{MPa})\end{array}$ & Poisson Ratio \\
\hline Composite & 15819 & 0.33 \\
\hline Paper & 11511 & 0.2 \\
\hline Impregnated Paper & 16357 & 0.35 \\
\hline
\end{tabular}

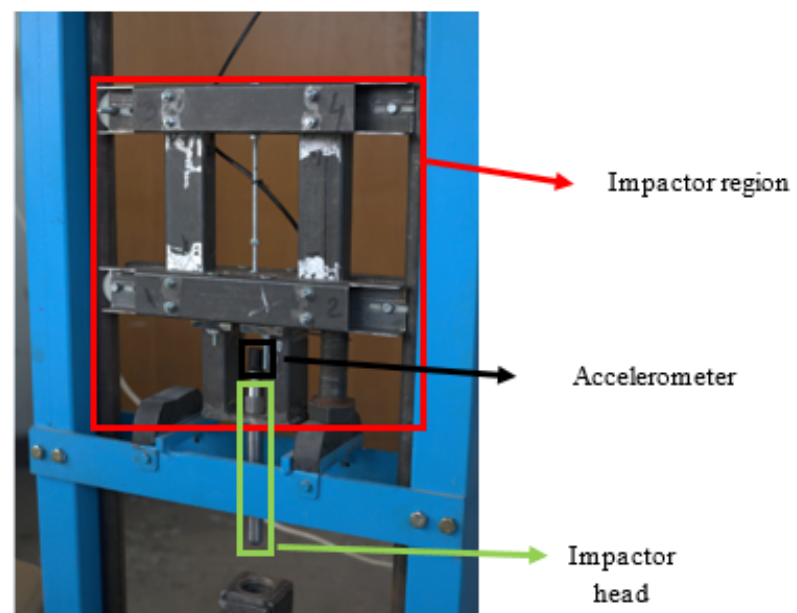

Fig. 8. Drop test impact tower

\section{Test conditions}

The multilayered honeycomb composite materials are tested for three energy levels: $5 \mathrm{~J}, 10 \mathrm{~J}$ and $15 \mathrm{~J}$. The energy level control is made by adjusting the distance between the multilayered honeycomb composite material and the impactor head. The test parameters are presented in table 2. The impact speed is determined using the mechanical energy conservation theory.

\section{Experimental testing}

To determine the behavior of the multilayered honeycomb composite material configurations to impact loading, on the three specified energy levels, in the linear elastic domain of the materials, three tests were performed for each composite material type. For each test case the acceleration was determined and a medium value was computed from the three results. On the following tables the experimental results are presented for each multilayered honeycomb composite material on each energy level. In the next tables the maximum acceleration values are given for each test case.

\begin{tabular}{|c|c|c|c|}
\hline Test case & $\begin{array}{c}\text { Energy level } \\
(\mathrm{J})\end{array}$ & $\begin{array}{c}\text { Impact speed } \\
(\mathrm{mm} / \mathrm{s})\end{array}$ & $\begin{array}{c}\text { Impact } \\
\text { distance }(\mathrm{mm})\end{array}$ \\
\hline 1 & 5 & 1216 & 75.4 \\
\hline 2 & 10 & 1720 & 150.8 \\
\hline 3 & 15 & 2107 & 226.2 \\
\hline
\end{tabular}

\begin{tabular}{|c|c|c|c|c|c|}
\hline $\begin{array}{c}\mathrm{V}=1216 \\
(\mathrm{~mm} / \mathrm{s})\end{array}$ & $\begin{array}{c}\text { Acceleration } \\
\text { Paper - Paper } \\
\left(\mathrm{m} / \mathrm{s}^{2}\right)\end{array}$ & $\begin{array}{c}\text { Acceleration } \\
\text { Paper - } \\
\text { Impregnated } \\
\text { Paper }\left(\mathrm{m} / \mathrm{s}^{2}\right)\end{array}$ & $\begin{array}{c}\text { Acceleration } \\
\text { Impregnated } \\
\text { Paper - Paper } \\
\left(\mathrm{m} / \mathrm{s}^{2}\right)\end{array}$ & $\begin{array}{c}\text { Acceleration } \\
\text { Impregnated Paper - } \\
\text { Impregnated Paper } \\
\left(\mathrm{m} / \mathrm{s}^{2}\right)\end{array}$ \\
\hline Test 1 & 1783.19 & 1982.24 & 1956.00 & 1649.42 \\
\hline Test 2 & 1730.71 & 1214.20 & 856.42 & 1831.19 \\
\hline Test 3 & 1109.23 & 1410.05 & 1713.42 & 1513.73 \\
\hline $\begin{array}{c}\text { Experimental } \\
\text { Medium Value }\end{array}$ & 1541.04 & 1535.50 & 1508.61 & 1664.78 \\
\hline
\end{tabular}

Table 3 EXPERIMENTAL RESULTS FOR THE FIRST ENERGY LEVEL ON ALL MULTILAYERED HONEYCOMB COMPOSITE MATERIALS 


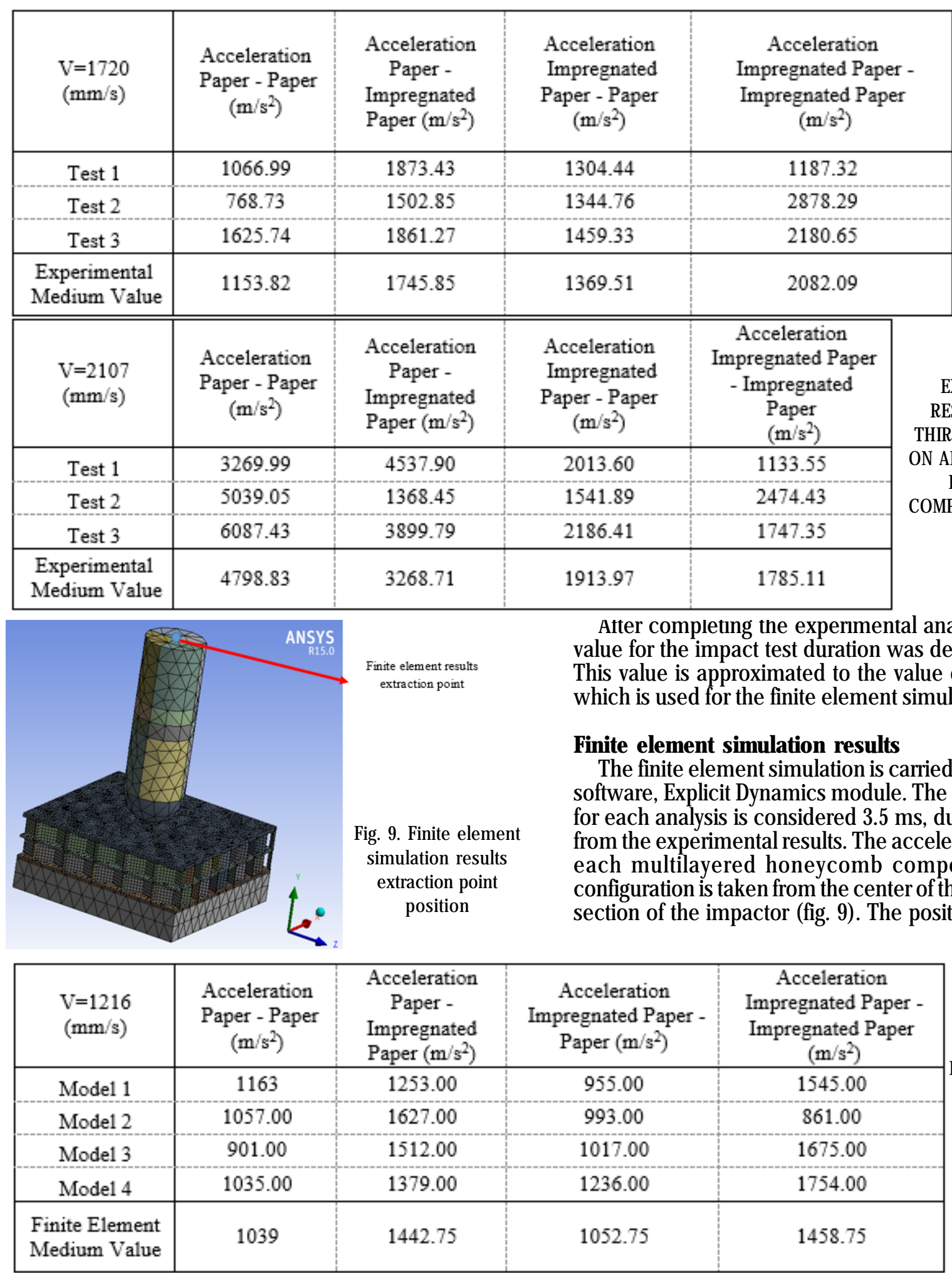

Table 4 EXPERIMENTAL RESULTS FOR THE SECOND ENERGY LEVEL ON ALL MULTILAYERED HONEYCOMB COMPOSITE MATERIALS

Table 5

EXPERIMENTAL RESULTS FOR THE THIRD ENERGY LEVEL ON ALL MULTILAYERED HONEYCOMB COMPOSITE MATERIALS

\begin{tabular}{|c|c|c|c|c|}
\hline $\mathrm{V}=1720(\mathrm{~mm} / \mathrm{s})$ & $\begin{array}{c}\text { Acceleration } \\
\text { Paper - Paper } \\
\left(\mathrm{m} / \mathrm{s}^{2}\right)\end{array}$ & $\begin{array}{c}\text { Acceleration } \\
\text { Paper - } \\
\text { Impregnated } \\
\text { Paper }\left(\mathrm{m} / \mathrm{s}^{2}\right)\end{array}$ & $\begin{array}{c}\text { Acceleration } \\
\text { Impregnated Paper - } \\
\text { Paper }\left(\mathrm{m} / \mathrm{s}^{2}\right)\end{array}$ & $\begin{array}{c}\text { Acceleration } \\
\text { Impregnated Paper - } \\
\text { Impregnated Paper } \\
\left(\mathrm{m} / \mathrm{s}^{2}\right)\end{array}$ \\
\hline Model 1 & 2063.00 & 1715.00 & 1887.00 & 1951.00 \\
\hline Model 2 & 1272.00 & 1779.00 & 1061.00 & 1592.00 \\
\hline Model 3 & 2534.00 & 1832.00 & 1551.00 & 2149.00 \\
\hline Model 4 & 1605.00 & 1860.00 & 1662.00 & 2583.00 \\
\hline $\begin{array}{l}\text { Finite Element } \\
\text { Medium Value }\end{array}$ & 1868.50 & 1796.50 & 1540.25 & 2068.75 \\
\hline
\end{tabular}

Table 6 FINITE ELEMENT RESULTS FOR THE FIRST TEST CASE ON EACH MULTILAYERED HONEYCOMB COMPOSITE MATERIALS
Table 7

FINITE

ELEMENT RESULTS FOR THE SECOND TEST CASE ON EACH MULTILAYERED HONEYCOMB COMPOSITE MATERIALS 
Table 8

FINITE ELEMENT RESULTS FOR THE THIRD TEST CASE ON EACH MULTILAYERED HONEYCOMB COMPOSITE MATERIALS

\begin{tabular}{|c|c|c|c|c|}
\hline $\mathrm{V}=2107(\mathrm{~mm} / \mathrm{s})$ & $\begin{array}{c}\text { Acceleration } \\
\text { Paper - Paper } \\
\left(\mathrm{m} / \mathrm{s}^{2}\right)\end{array}$ & $\begin{array}{c}\text { Acceleration } \\
\text { Paper - } \\
\text { Impregnated } \\
\text { Paper }\left(\mathrm{m} / \mathrm{s}^{2}\right)\end{array}$ & $\begin{array}{c}\text { Acceleration } \\
\text { Impregnated } \\
\text { Paper - Paper } \\
\left(\mathrm{m} / \mathrm{s}^{2}\right)\end{array}$ & $\begin{array}{c}\text { Acceleration } \\
\text { Impregnated Paper - } \\
\text { Impregnated Paper } \\
\left(\mathrm{m} / \mathrm{s}^{2}\right)\end{array}$ \\
\hline Mode1 1 & 2332.00 & 1930.00 & 3065.00 & 2262.00 \\
\hline Mode1 2 & 1713.00 & 2858.00 & 1840.00 & 2243.00 \\
\hline Mode1 3 & 2468.00 & 2891.00 & 1767.00 & 2960.00 \\
\hline Mode1 4 & 1717.00 & 2400.00 & 2257.00 & 3363.00 \\
\hline $\begin{array}{c}\text { Finite Element } \\
\text { Medium Value }\end{array}$ & 2062.00 & 2519.75 & 2232.25 & 2707.00 \\
\hline
\end{tabular}

\begin{tabular}{|c|c|c|c|c|}
\hline $\mathrm{V}=1216(\mathrm{~mm} / \mathrm{s})$ & $\begin{array}{c}\text { Acceleration } \\
\text { Paper - Paper } \\
\left(\mathrm{m} / \mathrm{s}^{2}\right)\end{array}$ & $\begin{array}{c}\text { Acceleration } \\
\text { Paper - } \\
\text { Impregnated } \\
\text { Paper }\left(\mathrm{m} / \mathrm{s}^{2}\right)\end{array}$ & $\begin{array}{c}\text { Acceleration } \\
\text { Impregnated } \\
\text { Paper - Paper } \\
\left(\mathrm{m} / \mathrm{s}^{2}\right)\end{array}$ & $\begin{array}{c}\text { Acceleration } \\
\text { Impregnated Paper - } \\
\text { Impregnated Paper } \\
\left(\mathrm{m} / \mathrm{s}^{2}\right)\end{array}$ \\
\hline $\begin{array}{c}\text { Experimental } \\
\text { Medium Value }\end{array}$ & 1541.04 & 1535.50 & 1508.61 & 1664.78 \\
\hline $\begin{array}{c}\text { Finite Element } \\
\text { Medium Value }\end{array}$ & 1039.00 & 1442.75 & 1052.75 & 1458.75 \\
\hline Error (\%) & 32.58 & 6.04 & 30.22 & 12.38 \\
\hline
\end{tabular}

Table 9

COMPARATIVE RESULTS FOR THE FIRST TEST CASE ON ALL MULTILAYERED HONEYCOMB COMPOSITE MATERIALS

\begin{tabular}{|c|c|c|c|c|}
\hline $\mathrm{V}=1720(\mathrm{~mm} / \mathrm{s})$ & $\begin{array}{c}\text { Acceleration } \\
\text { Paper - Paper } \\
\left(\mathrm{m} / \mathrm{s}^{2}\right)\end{array}$ & $\begin{array}{c}\text { Acceleration } \\
\text { Paper } \\
\text { Impregnated } \\
\text { Paper }\left(\mathrm{m} / \mathrm{s}^{2}\right)\end{array}$ & $\begin{array}{c}\text { Acceleration } \\
\text { Impregnated } \\
\text { Paper - Paper } \\
\left(\mathrm{m} / \mathrm{s}^{2}\right)\end{array}$ & $\begin{array}{c}\text { Acceleration } \\
\text { Impregnated Paper } \\
\text {-Impregnated Paper } \\
\left(\mathrm{m} / \mathrm{s}^{2}\right)\end{array}$ \\
\hline $\begin{array}{c}\text { Experimental } \\
\text { Medium Value }\end{array}$ & 1153.82 & 1745.85 & 1369.51 & 2082.09 \\
\hline $\begin{array}{c}\text { Finite Element } \\
\text { Medium Value }\end{array}$ & 1868.50 & 1796.00 & 1540.25 & 2068.75 \\
\hline Error (\%) & 61.94 & 2.90 & 12.47 & 0.64 \\
\hline
\end{tabular}

Table 10 COMPARATIVE RESULTS FOR THE SECOND TEST CASE ON ALL MULTILAYERED HONEYCOMB COMPOSITE MATERIALS

\begin{tabular}{|c|c|c|c|c|}
\hline $\mathrm{V}=2107(\mathrm{~mm} / \mathrm{s})$ & $\begin{array}{c}\text { Acceleration } \\
\text { Paper - Paper } \\
\left(\mathrm{m} / \mathrm{s}^{2}\right)\end{array}$ & $\begin{array}{c}\text { Acceleration } \\
\text { Paper } \\
\text { Impregnated } \\
\text { Paper }\left(\mathrm{m} / \mathrm{s}^{2}\right)\end{array}$ & $\begin{array}{c}\text { Acceleration } \\
\text { Impregnated } \\
\text { Paper - Paper } \\
\left(\mathrm{m} / \mathrm{s}^{2}\right)\end{array}$ & $\begin{array}{c}\text { Acceleration } \\
\text { Impregnated Paper - } \\
\text { Impregnated Paper } \\
\left(\mathrm{m} / \mathrm{s}^{2}\right)\end{array}$ \\
\hline $\begin{array}{c}\text { Experimental } \\
\text { Medium Value }\end{array}$ & 4798.83 & 3268.71 & 1913.97 & 1785.11 \\
\hline $\begin{array}{c}\text { Finite Element } \\
\text { Medium Value }\end{array}$ & 2062.00 & 2519.75 & 2232.25 & 2707.00 \\
\hline Error $(\%)$ & 57.03 & 22.91 & 16.63 & 51.64 \\
\hline
\end{tabular}

Table 11 COMPARATIVE RESULTS FOR THE THIRD TEST CASE ON ALL MULTILAYERED HONEYCOMB COMPOSITE MATERIALS takes into account the position of the accelerometer from the impact tower.

The finite element results for each test case on each geometrical model of the multilayered honeycomb composite materials, are given in the following tables. For each multilayered honeycomb composite material configuration on each test case a medium value is computed.

\section{Comparative results}

After completing the experimental and finite element analysis, the medium values were obtained for the impact accelerations on each multilayered honeycomb composite materials on the three energy levels. These results are presented in the tables from paragraphs 1.7 and 1.8. To make a comparative analysis between the experimental results in the finite element simulation, the results for the 
medium values are presented for each multilayered honeycomb composite material configuration on each load case in the following tables.

The error is computed using formula 1:

$$
\text { Error }=\left|\frac{E M V-F E M V}{E M V}\right|
$$

EMV - experimental medium value;

FEMV - finite element medium value.

Explanation:

Paper - Impregnated Paper - multilayered honeycomb composite material with impact on impregnated paper honeycomb layer;

Impregnated Paper - Paper - multilayered honeycomb composite material with impact on paper honeycomb layer.

\section{Conclusions}

The multilayered honeycomb composite materials on the first two test cases are tested in the linear elastic domain of the component materials.

The lowest errors were obtained for the impact on impregnated paper honeycomb layer.

For the third energy case the errors are significantly higher between the experimental and finite element analysis. In this case the component materials are no longer in the linear elastic domain, delamination and nonlinear deformations appear on the multilayered honeycomb composite materials.

The high error values for the multilayered honeycomb composite materials with impact on the paper layer, appear because in the finite element models, paper material was considered homogeneous material. This assumption was made because the difficulty of considering the natural mechanical properties of the paper material.

The finite element models used in the analysis, can be considered validated on the linear elastic domain of the multilayered honeycomb composite materials.

To make the experimental analysis on the multilayered honeycomb composite materials an impact tower was designed in the University Politehnica of Bucharest.

The finite element models of the multilayered honeycomb composite materials can be successfully used to determine the impact behavior of these materials, in the linear elastic domain.

\section{References}

1. GUEDRA-DE GEORGES, D., THEVENET, P., MAISON, S., Damage Tolerance of Aeronautical Sandwich Structures, Conference: Colloquium on Mechanics of Sandwich Structures (EUROMECH 360), St. Etienne Rouvra, France, 13-15 May, 1997
2. RYAN, S., RIEDEL, W. , SCHÄFER, F., Numerical Study of Hypervelocity Space Debris Impacts on Cfrp/Al Honeycomb Spacecraft Structures, $55^{\text {th }}$ International Astronautical Congress, Vol. 13, 2004, p. 8757-8767 3. WU, C.L., SUN, C.T., Low Velocity Impact Damage in Composite Sandwich Beams, Composite Structures, Vol. 34(1), 1996, p. $21-27$

4. LAKES, R., Deformation Mechanism in Negative Poisson's Ratio Materials: Structural Aspects, J ournal of material science, Vol. 26 (9), 1991, p. 2287-2292

5. MENNA, C., ZINNO, A., ASPRONE, D., PROTA, A., Numerical Assessment of the Impact Behavior of Honeycomb Sandwich Structures, Composite Structures, Vol. 106, 2013, p. 326-339

6. YAN, P. L., ZHANG, L.X., Improved Shielding Structure with Double Honeycomb Cores for Hyper-Velocity Impact, School of Aerospace Engineering, Mechanics Research Communications, Vol. 69, October 2015, p. 34-39

7. ABRATE, S., Impact Engineering of Composite Structures, Book Series: CISM Courses and Lectures Issue: 526 Springer, Book Series: CISM Courses and Lectures Issue: 526, 2011

8. PIERSON, A.G., PAEZ, T.L., Harris's Shock and Vibration Handbook, Sixth edition, Mc Graw Hill, 2010

9. HEARD, B.J., Handbook of Firearms and Ballistics, Second edition, Wiley-Blackwell, 2008

10. GANESH BABU, M., VELMURUGAN, R., GUPTA, N.K., Energy Absorption and Ballistic Limit of Targets Struck by Heavy Projectile, Latin American Journal of Solids and Structures, Vol. 3, 2006, p. 21-39 11. REYES, G., Aluminum Foam Core Static and Low Velocity Impact Behavior of Composite Sandwich Panels, Journal of Composite Materials, Vol. 42(16), 2008

12.DANIEL, I. M., ImpactResponse and Damage Tolerance of Composite Sandwich Structures, Dynamic failure of materials and structures, Edited by: Shukla, A., Ravichandran, G., Rajapakse, Y.D.S., 2010, p. 191-233

13. BUTUKURI, R., BHEEMREDDY, V., CHANDRASHEKHARA, K., SAMARANAYAKE, V., Evaluation of Low-Velocity Impact Response of Honeycomb Sandwich, J ournal of Sandwich Structures and Materials, Vol. 14(3), 2012

14. LEE, I.T., SHI, Y., AFSAR, A.M., OCHI, Y., BAE, S. I., SONG, J.I., LoW Velocity Impact of Aluminium Honeycomb Structures, Advanced Composite Materials, Vol. 19 (1), 2010

15. GALEHDARI, S.A., KADKHODAYAN, M., HADIDI-MOUD, S., Analytical, Experimental and Numerical Study of a Graded Honeycomb Structure Under In-Plane Impact Load with Low Velocity, International J ournal of Crashworthiness, Vol. 20(4), 2015

16. YAMASHITA, M., GOTOH, M., Impact Behavior of Honeycomb Structures with Various Cell Speciûcations Numerical Simulation and Experiment, International Journal of Impact Engineering, Vol. 32(14), 2005, p. 618-630

17. AKIL HAZIZAN, M., CANTWELL, W.J., The Low Velocity Impact Response of an Aluminium Honeycomb Sandwich Structure, Composite Structures, Vol. 34(8), 2003, p. 679-687

Manuscript received: 15.10 .2016 